\title{
Creative Solutions to Technical Services Staffing Challenges in an Academic Library
}

\author{
Meghan Banach Bergin and Sally Krash
}

\section{ABSTRACT}

This chapter discusses staffing challenges faced by the information resources management (IRM) department at the University of Massachusetts Amherst Libraries and how they were solved. The IRM department (acquisitions unit, discovery and resource management systems unit, metadata unit, and materials management unit) has experienced significant changes in the last few years and recently engaged in several initiatives aimed at assessing and revising staffing and workflows to adapt to these changes. In 2014 the dean of the libraries and the Libraries' administration team commissioned an IRM department workflow review task force and charged the group with writing a report that included an environmental scan of peer institutions, survey results from internal staff surveys, and recommendations on how to move the department forward. In 2016 the IRM department built on the work of the task force by developing and engaging in several new processes. This chapter will explain in detail how the department successfully dealt with staffing issues such as retirements and changing job duties. The department is now better able to manage its workload and has even been able to take on some important new tasks, including doing internal outreach to the Libraries' administration team and other departments in the Libraries to raise awareness about the important work done in the IRM department. 


\section{BACKGROUND}

The UMass Amherst Libraries' dean and administration team commissioned an the information resources management (IRM) workflow review task force in 2014 to look at the ways technical services workflows were changing and make recommendations on how best to respond to the evolving nature of the work. The task force was charged with conducting an environmental scan of technical services operations at peer libraries that explored functions and responsibilities, reporting lines, and workflows other libraries have eliminated, changed, or added. The task force found that while each library organized its staff in a slightly different way, they are all trying to deal with the same shift from managing physical materials to managing licensed electronic resources, local digital collections, and open access materials. They found that priorities in technical services units at other academic libraries mirrored many of the UMass Amherst Libraries' and the IRM department's own priorities, such as discovery and access, electronic resources management, institutional repositories, non-MARC metadata, and batch loading and batch editing vendor records for e-resources. The task force also found that many academic libraries had experienced reorganizations, loss of staff, and changes in functions in their technical services departments. In addition to the environmental scan, the task force gathered feedback from UMass Amherst libraries staff in general and the IRM department staff in particular. The feedback they received about what IRM does well included responding to users' needs and managing an overwhelming amount of information. Several IRM staff mentioned communication and training as areas in which they could improve, and staff outside of IRM said that linking to electronic resources was sometimes a problem. Feedback from IRM staff about what new positions they needed included a new department head (the current department head was planning to retire soon), more staff to manage electronic resources, and at least one additional professional cataloger/metadata librarian. To better meet the needs of users regarding discovery and access to the Libraries' information resources, the IRM workflow review task force recommended that the department do the following: 
- Shift our organization to focus more on managing electronic resources and less on managing physical collections

- Continually look for ways to streamline processes and create more efficient workflows

- Standardize procedures to make more processes routine

- Distribute responsibility more broadly and equitably through the department

- Empower decision-making at the lowest possible level

- Establish clear priorities for the work that is done in the department

- Consider implementing a comprehensive library software platform that embraces the concept of a shared community record

- Consider implementing CORAL as an electronic resources management (ERM) tool

- Hire a new IRM department head

- Hire additional electronic resources management staff (one librarian and one classified staff position)

- Hire a metadata librarian

- Hire a user experience librarian who could conduct user studies and help design, improve, and support the Libraries' primary user interfaces, including the website, the catalog, the discovery system, and digital library collections

\section{DEVELOPING AN ACTION PLAN}

When the new head of the information resources department was hired, her first order of business in moving the recommendations of the task force report forward was to develop an action plan with a timeline detailing each step required to accomplish the reorganization. The IRM leadership team, consisting of the four unit coordinators and new department head, began looking at what needed to happen to move toward a more efficient 21st-century technical services operation. An action plan was developed, reviewed, revised, and established. Details of the action plan can be found can be found on the IRM wiki. ${ }^{1}$ The action plan included the following elements: (1) a 
review and discussion of the proposed action plan at every level of the department leading to finalization of the plan, (2) documenting and reviewing current workflows, (3) conducting an in-depth analysis of workflows, (4) facilitating a card sort activity by all staff to group like things together as the basis for an evolved departmental model, (5) analyzing of the results of the card sort activity, (6) identifying possible models for the departmental reorganization, (7) conducting pre-implementation work by reviewing and revising job descriptions and determining how training would occur, and (8) implementing the plan. The entire reorganization process was expected to take 14 months and be in place by the end of the 2017 fiscal year.

The action plan was developed in January and February of 2016 then presented to staff in March at a department meeting. Staff reviewed and discussed the plan in individual unit meetings. Some adjustments were made as a result of those meetings, and the final plan was presented to staff at the end of April. At the April meeting, workflows were discussed and worksheets were made available for staff to assist with workflow analysis.

\section{REVIEW OF CURRENT WORKFLOWS}

With the change from collecting and supporting (primarily) print resources to collecting and providing access primarily to e-resources, the focus of IRM has changed significantly in recent years. However, some current workflows include legacy processes that either are no longer necessary or need to be revised. Additionally, there are workflow processes (such as usability testing for e-resources) that need to be added into their workflows. This is necessary to support the Libraries' campus user community moving forward.

The first major phase of the action plan was to list all the workflows in each of the units (metadata, acquisitions, materials management, and discovery and resource management systems). Each staff member in the department took responsibility for documenting the workflows they did on a regular basis. Staff also tried to identify workflows they thought the department could let go of doing and decided that print serials binding could be eliminated, the number of microfilms they were ordering could be reduced, book plating 
gift books could cease, and LOCKSS journal preservation processing could be discontinued.

The current workflows analyzed in each unit are listed below.

\section{Acquisitions unit}

Manage acquisitions budget

Manage demand-driven acquisitions plans

Manage approval plans

Manage subscription resources (renew, cancel, etc.)

Negotiate license agreements

Acquisitions order processing

Acquisitions invoice processing

Electronic resource management system records

Administer database trials

E-resources outreach and publicity

E-resources access troubleshooting

Compiling usage statistics for e-resources

Proxy server management

Discovery platform management

LOCKSS preservation processing

Link resolver records management

\section{Materials management unit}

Physical processing/labeling (all formats)

Book plating

Bindery operations

Book repair

Transfer processing (depository, OCA, etc.)

Records linking

Withdrawals

\section{Metadata unit}

Metadata creation/transformation

Name authority records creation and editing

Copy cataloging (all formats)

Original cataloging (all formats)

Serials records management

Reinstatements 
Replacements

Withdrawals

Shelf-ready book receiving

Non-shelf-ready book receiving

DVD receiving

Records linking

Transfer processing (depository, OCA, etc.)

Batch loading and editing e-resources records

\section{Discovery and resource management systems unit}

Aleph client configuration and installation

Aleph support for Five Colleges (Amherst College, Hampshire College, Mount Holyoke College, Smith College, and University of Massachusetts Amherst)

Batch loading and editing e-resources records

Create and monitor computerized processes

NCIP patron record loads for commonwealth catalog

Support desk ticket system administration

Maintain Oracle tables configuration

Specialty database creation

Managing HathiTrust records

OCLC and RAPID holdings batch updates

Generating reports out of the Aleph Reporting Center

EBSCO GOBI Electronic Order Confirmation Records loading

One of the main goals of this process was to redistribute the work among the units more evenly. Some units like metadata and acquisitions had more work than they could handle, but in other units such as materials management the work was decreasing. Ultimately, both workflows and staff were reorganized among the units to meet this goal. This was achieved through an iterative process, which involved a card sort activity at a departmental staff retreat and subsequent discussions in meetings following the retreat.

\section{CARD SORT ACTIVITY}

After evaluating existing workflows and analyzing what needed to be discontinued, changed, or added, the department needed to move 
forward to determine a new organizational structure. The newly hired head of the IRM department contacted the UMass workplace learning and development (WL\&D) office to discuss its availability to assist with developing options for the new structure. WL\&D provides programs and services that support organizational growth and staff development. WL\&D staff were able to facilitate a departmental retreat that included a card sort activity and affinity diagram exercise. Card sorting is generally used to help design and develop online platforms. In this activity users of the platform sort like things together to inform the architecture for a new or reimagined user experience. The goal is to create a viable usable structure. There are many examples of card sorting available online, including YouTube videos. Affinity diagrams are similar in that they show categories of large amounts of data organized into natural relationships.

The purpose of planning this retreat was to provide staff with the opportunity to express their thoughts and opinions about the connections of current workflows and to share feedback on how workflows within the department could be realigned. The goal for this activity was to develop a framework for a new organizational structure.

First, the head of the information resources management department met with a representative from WL\&D to review needs and expectations. A meeting agenda was planned that included the following activity:

1. Create cards-one for each major workflow (full pack for each group)

2. Divide department personnel into four to six groups for this activity

3. Each group will sort like workflows into separate categories

a. For existing workflows

b. For how workflows should be grouped going forward

4. Record the results from each group

5. Provide typed notes and the results from each group to the IRM department

There were several communications to develop and finalize an agenda for the retreat, which included a 30-minute introduction to card sorting and affinity diagrams, a 1-hour card sort activity, and $1 \frac{1}{2}$ hours for analysis and development of affinity diagrams. The 
activity was conducted in the allotted time, included all IRM staff (no one was out that day), and took the entire 3 hours designated.

When participants entered the room, they pulled a card from a grab bag and sat at one of four tables labeled the same as their card (A-D). This provided random groups, although one table had mostly cataloging staff so some shuffling was done. Besides facilitating the retreat, WL\&D provided sticky notes (the cards), markers, and easel pad paper for each of the four groups.

After learning the details of card sorting and affinity diagrams, participants at each table started categorizing their sticky note workflows on the easel pad paper adhered to the wall next to their table. They were instructed to first put up their sticky notes without talking, then after all notes were in place they could discuss and move workflows. It was interesting to watch the group dynamics: some staff had a hard time keeping silent; some moved a workflow to a particular category, only to have someone else move it elsewhere, followed by the original staff member moving it back (sometimes this went on for a while); and some identified processes that they initially failed to include in their workflow listing. (See figure 14.1.)

After the session concluded, everyone walked away feeling engaged in the process of developing a final organizational structure, but also a bit overwhelmed by it. They discussed what they had learned and what they thought needed to happen as they awaited final deliverables from WL\&D.

Final deliverables included workflow affinity diagrams for each of the four groups (images and typed-up lists) as well as overall notes on workflow designs: similarities, differences, and processes not included in the initial list of workflows. Analysis of the card sorting activity included looking at the four main categories that corresponded to existing units: acquisitions, discovery and resource management, materials management, and metadata. For each category, any function that was identified by two or more groups was labeled "common among groups." Any workflow that was only selected by one group was labeled "unique."

Each group identified an acquisitions category. There were no surprises among workflows that were common among groups. Some groups did not know where to put things like troubleshooting electronic resources and loading records, and those were placed in the unique label. (See figure 14.2.) 


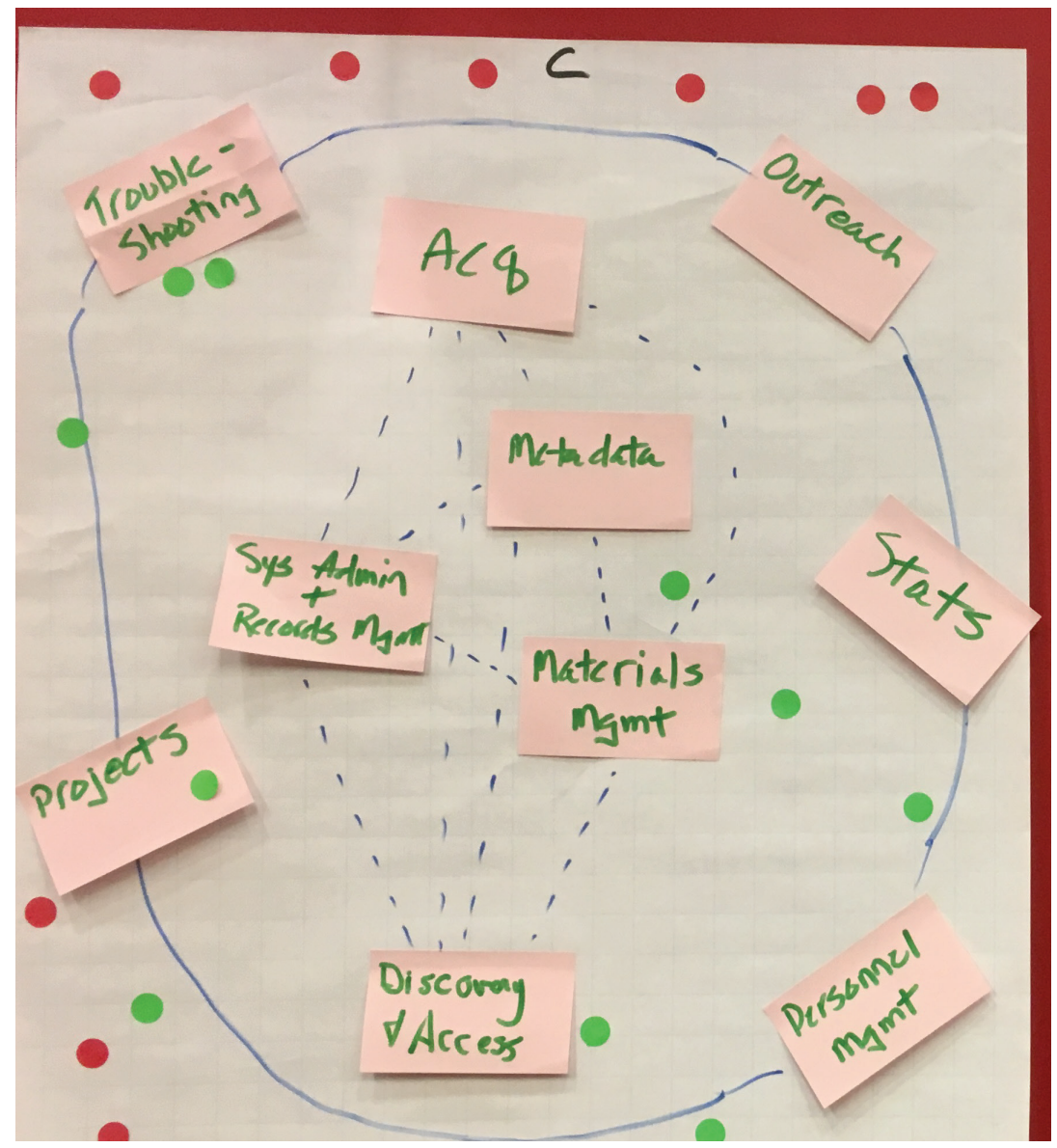

Figure 14.1 Affinity diagram example.

Each group identified a systems category. There were many overlapping workflows in this category, but most dealt with systems, Oracle administration, and various aspects of records management. Each group identified a cataloging/metadata category. There were few surprises here, with many overlapping records management workflows with other units. The physical management category was the most interesting. Many workflows were questioned, like book plating and bindery operations. It was generally believed that this unit had the most flexibility in being dismantled and moved into other areas of the department. Records management functions spanned all units but fell primarily under metadata and discovery and resource management systems functions. (See figure 14.3.) 


\section{Workflow Affinity Document ACQUISITIONS/ACQUISITIONS UNIT}

\section{Common among groups:}

- Manage Acquisitions Budget

- Manage Demand Driven Acquisitions Plans

- Manage Approval Plans

- Manage Subscription Resources (Renew, Cancel, etc.)

- Negotiate License Agreements

- Acquisitions Order Processing

- Acquisitions Invoice Processing

- Electronic Resource Management System Records Management

- Administer Database Trials

\section{Unique:}

- Group A:

- EDI Invoice Loading (currently handled by DRMS Unit)

- Group B:

- None

- Group C:

- Replacements (Purchasing replacements)

- Group D:

- Link Resolver Records Management (currently handled by DRMS Unit)

- Usability Testing (proposed that DRMS Unit take the lead)

- Electronic Resources Outreach (currently handled by Acquisitions Unit)

- Electronic Resources Access Troubleshooting (Acquisitions Unit and DRMS Unit?)

- Compile COUNTER and non-COUTNER Statistics (currently handled by Acquisitions Unit)

\section{Workflow - 1}

Figure 14.2 Acquisitions category with notes. 


\section{Workflow Affinity Document \\ PHYSICAL/MATERIALS MANAGEMENT UNIT}

\section{Common among groups:}

- Bookplating

- Physical Processing (all formats)

- Bindery Operations

- Physical Material Maintenance

- Transfer Processing (Depository, OCA, etc.)

- SCUA Preservation

- Preservation Outreach

- Records Linking

- Withdrawals (MU and MMT)

- Shelf Ready Books Receiving (2 out of the 4 groups thought this should stay in cataloging)

\section{Unique:}

- Group A:

- None

- Group B:

- None

- Group C:

- Withdrawals (MU and MMT)

- Group D:

- Reinstatements (decided in MU/MMT meeting to keep this in MU Unit)

- Replacements (decided in MU/MMT meeting to keep this in MU Unit-purchases handled by Acquisitions Unit)

- DVD Receiving (currently in MMT)

- Non-shelf Ready Book Receiving (currently in MU)

\section{Workflow - 4}

Figure 14.3 Physical category with notes. 
Several categories spanned the entire department and were labeled "halo" categories. Those were viewed as categories that could not be subsumed by just one unit. In drawing out possible reorganization strategies, those workflows were kept on the periphery of possible new organizational structures in the affinity diagrams.

\section{DEPARTMENT ORGANIZATIONAL MODELS}

During the analysis piece, each group presented their diagram and discussed how they arrived at each category and what they had added that had been left out. The next step was to reconvene as groups and develop affinity diagrams based on their findings. The facilitator then put the diagrams next to each other at the front of the room and staff voted by placing colored dots on the diagrams they liked most and least. There was one diagram that got significantly more votes than any other, so they looked more closely at that diagram. The facilitator drilled down into the workflow categories on that diagram, looking for similarities and differences.

All interactions were captured and documented by the facilitator and provided as a follow-up to the activity. Documents were then shared and discussed at both unit and department-wide meetings. In reviewing the documentation, staff combined needs, discards, and shifts to come up with two possible models for reorganization. The first model was very similar to the existing departmental structure and included the existing four units with some overlap and changes. The second model eliminated the materials management unit and consolidated much of the systems maintenance and bulk records management activities into the discovery and resource management systems unit.

Final discussion about the new organizational structure occurred at the November 2016 IRM department meeting. The second model was selected, which meant that the materials management team would be subsumed into the acquisitions unit. Two staff members from the former materials management unit moved into the acquisitions unit to help with e-resources management as bindery work and physical materials processing decreased. Some workflows that were originally done in the acquisitions unit were moved into the discovery and resource management systems unit, such as proxy server management, discovery platform management, and link resolver records management. Two 
staff members from the acquisitions unit moved into the discovery and resource management systems unit to help with these workflows. And finally, shelf-ready book and DVD receiving were moved from the metadata unit to staff in the acquisitions unit.

The leadership team then started reviewing and updating job descriptions. As staff were moved into different units and took on new responsibilities, it was necessary to rewrite job descriptions and provide training. A shared spreadsheet workbook was created, showing each of the three major units (one unit per tab). The job descriptions for each staff member were transferred into the workbook on the corresponding unit tab. To remove classism from the new departmental structure, job titles were streamlined and renamed. All paraprofessional staff members became specialists. For example, cataloging assistants became metadata specialists. The unit coordinators felt the job title "specialist" more accurately represented the high level of expertise the paraprofessionals possess. They often perform similar job duties to professional librarians or possess advanced technical skills. Job duties were aligned, showing which duties were shared among all staff working in each unit. Using the metadata specialist as an example, each staff member had about 10 main job duties. Seven of those duties were aligned with the same language for each staff member. Each staff member also had 2 to 4 job duties that were unique. Along with those unique duties, backup functionality was incorporated so that for each unique duty, there was a person who could perform backup whenever the main staff member was out. Seeing all the job descriptions lined up side by side in a spreadsheet made it much easier for the head of library human resources to see the similarities in job duties between each staff member. Because of this easy comparison and the fact that some staff took on more complex job duties, the Libraries' administration team was able to justify several staff having their positions upgraded. Training was done in-house using a peer-to-peer training model, and all staff are now successfully working with their new job duties.

The following list shows how units and workflows changed after the card sort activity.

\section{Acquisitions unit}

Manage acquisitions budget

Manage demand-driven acquisitions plans

Manage approval plans 
Manage subscription resources (renew, cancel, etc.)

Negotiate license agreements

Acquisitions order processing

Acquisitions invoice processing

Administer database trials

E-resources outreach and publicity

E-resources access troubleshooting

Compiling usage statistics for e-resources

LOCKSS preservation processing (eliminated)

Physical processing/labeling (subsumed into acquisitions unit from former materials management unit)

Transfer processing to off-site storage facilities (subsumed into acquisitions unit from former materials management unit)

Records linking/barcoding (subsumed into acquisitions unit from former materials management unit)

Processing discarded material (subsumed into acquisitions unit from former materials management unit)

*Shelf-ready book receiving (moved from metadata unit)

${ }^{*}$ DVD receiving (moved from metadata unit)

*Book plating (eliminated)

*Bindery operations (drastically reduced)

*Book repair (moved into special collections and university archives)

\section{Metadata unit}

Metadata creation/transformation

Name authority records creation and editing

Copy cataloging (all formats)

Original cataloging (all formats)

Serials records management

Reinstatements

Replacements

Withdrawals

Non-shelf-ready book receiving

Records linking/barcoding troubleshooting

*Batch vendor records loading (shared with discovery and resource management systems unit) 


\section{Discovery and resource management systems unit}

Aleph client configuration and installation

Aleph support for Five Colleges (Amherst College, Hampshire College, Mount Holyoke College, Smith College, and University of Massachusetts Amherst)

*Batch vendor records loading (shared with metadata unit)

Create and monitor computerized processes

NCIP patron record loads for commonwealth catalog

Support desk ticket system administration

Maintain Oracle tables configuration

Specialty database creation

Managing HathiTrust records

OCLC and RAPID holdings batch updates

Generating reports out of the Aleph Reporting Center

EBSCO GOBI Electronic Order Confirmation Records loading

${ }^{*}$ CORAL Electronic resource management system maintenance (moved from acquisitions unit)

*Proxy server management (moved from acquisitions unit)

*Discovery platform management (moved from acquisitions unit)

*Link resolver records management (moved from acquisitions unit)

\section{CONCLUSION}

The IRM department's staffing, workflow review, and reorganization process was thorough, well thought out, and iterative. The effort was led by the head of the IRM department and the three IRM unit coordinators, with support from the dean of libraries and the Libraries administration team. There was good communication throughout the whole process, and staff were given many opportunities for input. Everyone in the IRM department was involved in the decision-making process, and there was ample time to discuss changes and answer questions. Some staff got raises and others voluntarily moved into other units or took on new job duties. No one was forced to make changes before they were ready or without proper training. As a result, there was strong buy-in, and staff adapted well to the changes that were made. 
The department was able to streamline or eliminate several workflows, which allowed staff and financial resources to be devoted to new initiatives such as usability testing for the newly implemented EBSCO discovery system or to higher-priority work such as cataloging hidden collections. Staff were able to cut down on the time spent reviewing catalog records for shelf-ready books by outsourcing via the OCLC Cataloging Plus service. This also allowed staff to batch receive books an entire invoice at a time rather than receiving books one by one and having to review each catalog record individually as they used to do. The department cut back on binding and purchasing microfilm and devoted more staff to e-resource management, updated job descriptions, and provided training for staff who used to spend most of their time working with print materials.

Another benefit of this process was that it brought positive attention to the IRM department at a time when staff were looking to highlight all the important work they do behind the scenes. The Libraries' director for human resources and the dean of the libraries were supportive of the department's efforts to revise job descriptions and upgrade staff positions, because the department had suffered the loss of so many staff due to retirements and because they understood that the nature of the work was changing. The university's central human resources office was also supportive because the Libraries' director of human resources was able to show that upgrades were justified due to staff members taking on higher-level job duties. The library administration team is now interested in using the IRM workflow review process as a model for reviewing staffing, workflows, and organization in other departments in the UMass Amherst Libraries.

\section{NOTE}

1. "IRM Evolving Workflows," August 25, 2017, accessed January 16, 2018. http://www.library.umass.edu/wikis/acp/doku.php?id =evolving_workflows_-_2016. 